\title{
БЕЗОПАСНОСТЬ ВОДНОГО ТРАНСПОРТА: ПРОБЛЕМЫ НАДЗОРА ЗА СОБЛЮДЕНИЕМ ТРЕБОВАНИЙ В ОТРАСЛИ
}

\section{THE SAFETY OF WATER TRANSPORT: PROBLEMS OF SUPERVISION OVER COMPLIANCE WITH THE REQUIREMENTS IN THE INDUSTRY}

\section{Markov}

Summary. An important area of ensuring water transport safety is the supervision of compliance with the requirements in this area. The results of the administrative reform show that the statistics of violations of water transport safety requirements are the result of systemic problems in the state administration of the water transport system. The solution to the problems of ensuring the safety of the water transport industry is seen through the introduction of domestic innovative developments.

Keywords: transport supervision, safety, GosMorRechNadzor, water transport development programs.

\section{Актуальность}

B ажнейшее значение для развития народного хозяйства имеет деятельность по обеспечению транспортной безопасности. Данный тезис строится на положении о том, что аварийность на водном транспорте определяет больше экономические потери. Поэтому крайне важно обосновать и соблюдать систему мер, обеспечивающих профилактику и снижения тяжести последствий нарушению безопасности. Данная компетенция обеспечивается посредством специально организованного надзора. Рост масштабов современного судоходства определил необходимость проведения административных реформ в данной отрасли, итогом чего стало функционирование бассейновых управлений государственного надзора за работой внутреннего водного транспорта, у которых надзорные компетенции после реформы расширились [8]. При этом следует учитывать, что по-прежнему научно обоснованных предложений по организации работы системы безопасности на водном транспорте нет, несмотря на то, что существует социальный запрос. Установлено, что большая часть аварийных ситуаций на водном транспорте объясняется человеческим фактором и нарушением нормативных актов. Усилия бассейновых управлений государственного надзора позволили сократить в целом число инцидентов, но в отдельных бассейнах рек существуют проблемы безопасности судоходства, убытки от которых
Марков Владимир Петрович

Д.ю.н., дочент, ФГБОУ ВО «Самарский государственный экономический университет» sf-vguvt@mail.ru

Аннотация. Важным направлением обеспечения безопасности водного транспорта остается надзорная деятельность за соблюдением требований В данном направлении. Результаты проведенной административной реформы показывают, что статистика нарушения требования к безопасности водного транспорта является следствием системных проблем в органах государственного управления системой водного транспорта. Решение проблем обеспечения безопасности отрасли водного транспорта видится посредством внедрения отечественных инновационных разработок.

Ключевые слова: транспортный надзор, безопасность, Госморречнадзор, программ развития водного транспорта.

значительные. Соответственно, надзор за соблюдением требований к безопасности в транспортной отрасли весьма актуален, так как истоки существующих проблем организации безопасности водного транспорта кроются во взаимоотношениях между уровнями власти [2].

\section{Цель статьи}

Анализ существующих проблем организации надзора за соблюдением требований безопасности на водном транспорте Российской Федерации.

\section{Метолика}

В процессе написания статьи использовались материалы публикаций, где дается оценка современному состоянию проблем в сфере обеспечения надзора за безопасностью водного транспорта, и объясняющих их предпосылок. Отдельное внимание уделено анализу диссертаций, разрывающие научно-методические положения организации безопасности водного транспорта в разрезе конкретного региона.

\section{Основное изложение статьи}

Анализ различных точек зрения позволяет установить, что рентабельность перевозок грузов и пассажиров внутренним водным транспортом сохраняется, од- 
Таблица 1. Субъекты надзора за безопасностью внутреннего водного транспорта [Источник: 6]

\begin{tabular}{|l|l|}
\hline Тип поднадзорного субъекта & 2020 год \\
\hline Организации, эксплуатирующие портовые и судоходные гидротехнические сооружения & 6299 \\
\hline Капитаны бассейнов внутренних водных путей & 834 \\
\hline Лоцманские организации & 15 \\
\hline
\end{tabular}

нако данный вид транспорта в Российской Федерации на грани полного исчезновения. Одной из причин является надзорная деятельность субъектов транспортной безопасности на водном транспорте. Основная хроническая проблема - это устаревший парк судов. Согласно данным Минтранса РФ, только 25\% внутренних речных судов находятся в идеальном состоянии [7]. Именно возрастные проблемы внутреннего речного транспорта стали причиной ужесточения контроля за техническим состоянием водного транспорта и его обязательного страхования. В отдельных регионах страны работа внутреннего водного транспорта определяет жизнедеятельность удаленных районов. Старые и неисправные речные суда списываются медленными темпами. Анализ различных источников позволил установить, что объективными ограничениями для безопасности водного транспорта выступают гидрологические условия (мелководье, недостаток водности, занос судовых ходов донными отложениями), стагнация в экономике (спад производства и строительства, банкротство компаний и платежеспособность грузоотправителей и конкуренция с другими видами транспорта) [1]. Кроме того, отдельными специалистами констатируется, что чиновниками принимается много программ развития водного транспорта в стране, но особо ничего не делается. Таким образом, у надзорных органов в сфере обеспечения безопасности водного транспорта будет много вопросов, решение которых видится на межведомственной основе [5, c. 147-152].

Действующее законодательство не может воплотиться транспортные отношения в сфере обеспечения безопасности без уполномоченных субъектов. В Кодексе внутреннего водного транспорта РФ (ред.2.08.2019) определено, что структурным подразделением надзора, входящим в Ространснадзор, является Госморречнадзор, в компетенцию которого входят вопросы безопасности внутреннего водного транспорта. По мнению отдельных исследователей, с появлением этих органов смысл категории «надзор» получил новое практическое содержание: отмечается усиление правового воздействия на сферу обеспечения безопасности, в том числе и внутреннего водного транспорта [3, с. 8-19]. Обращение к отчетным документам Госморречнадзора показывает, что главной причиной, определяющей высокий риск нарушения безопасности водного транспорта, является нарушение технических регламентов. Организация действует через сеть территориальных органов. Кроме того, им приходится нередко взаимодействовать со специально уполномоченными органами в сфере безопасности. В Таблице 1 представлен перечень субъектов надзора по состоянию на начало 2020 г.

В процессе изучения проблематики надзора в сфере транспортной безопасности важно учитывать мнения и тех, кто непосредственно стоит у штурвала внутреннего водного транспорта. М.А. Кирилин, представляющий ассоциацию транспортников, обращает внимание на большие объемы финансирования программ развития водного транспорта, однако это не уменьшает проблемы внедрения инновационных технологий в сферу внутреннего водного транспорта. На первый план выходит проблема государственной поддержки российских производителей оборудования для обеспечения безопасности водного транспорта: делают новые суда, а по импорту завозят иностранное дорогостоящее оборудование. Зачастую конкурсные заявки на инновационные разработки выигрывают «нужные» компании. Фактически созданы благоприятные условия для использования зарубежного оборудования, обеспечивающего безопасность водного транспорта. М.А. Кирилиным приводится немало примеров ситуаций, когда конкурсы на поставки судового оборудования выигрывают отечественные производители. Проблема заключается в отношениях между уровнями власти: Росморречфлот не имеет контрольных полномочий для влияния на эти процессы. Поэтому, даже если конкурс выигран отечественным поставщиком, часто решение по нему может откорректировать конкретный орган исполнительной власти из столицы [4]. Подобные факты становится часто объектом внимания органов прокуратуры и других государственных органов, потому что в сфере водного транспорта, как и в других отраслях, конкурсы на поставки оборудования выигрывают одни и те же компании. Решение данной проблемы видится в передаче полномочий отраслевым организациям по распоряжению целевыми бюджетными средствами, а не чиновникам. В подобных условиях развивать подходы к безопасности на водном транспорте малоэффективно, так как нет импульса для отечественного приборостроения, проектирующего технологии на основе знания о специфике водных бассейнов страны. 
Шире смотри на проблемы безопасности водного транспорта страны П.М. Ермолаев, ранее возглавлявший Управление государственного морского и речного надзора [2]. По его мнению, важное значение для безопасности водного транспорта имеет внедрение технологических инноваций, позволяющих автоматизировать процессы обеспечения безопасности на водном транспорте и сократить количество проверок. Одной из таких инноваций является автоматизированное рабочее место транспортного инспектора, разработанное компанией «Морсвязьспутник», возможности которого повышают эффективность надзора за водным транспортом.

Выводы. Подведение итогов статьи позволяет отметить нерешенность большинства вопросов в сфере обеспечения безопасности внутреннего водного транспорта страны. Выделенные в статье проблемы рассматриваются как наиболее актуальные на современном этапе. Уста- новлено, что большинство проблем обеспечения безопасности отрасли кроется во взаимоотношениях между уровнями государственной власти, в межведомственном взаимодействии, на которые отраслевые организации не способны оказывать влияния. Принятие целевых программ на федеральном уровне не способствует развитию системы безопасности водного транспорта в полном объеме, а кормит дорогостоящими заказами зарубежного приборостроителя. В подобных условиях обновлять парк водного транспорта видится проблематично. Чтобы законодательство о безопасности заработало, необходимо отношения в сфере обеспечения безопасности, в том числе обеспечение речных судов дешевым отечественным оборудованием, необходимо расширять надзорные компетенции Госморречнадзора (который все замечает в отрасли водного транспорта, но ничего сделать не может), и ограничивать полномочия Минпромторга РФ.

\section{ЛИТЕРАТУРА}

1. Гусаченко Н. Новые объемы и старые проблемы: итоги речной навигации 2019 года / Н. Гусаченко / Материалы информационного агентства РЖД-партнер. - [Электронный ресурс].— Режим доступа: https://www.rzd-partner.ru/wate-transport/reviews/novye-obemy-i-starye-problemy-itogi-rechnoynavigatsii-2019-goda/ (дата обращения: 20.03.2020).

2. Доклад П. М. Ермолаева «Совершенствование государственного контроля и надзора в сфере обеспечения безопасности на водном транспорте» / Портал korabel.ru. — [Электронный ресурс].— Режим доступа: https://www.korabel.ru/ (дата обращения: 21.03.2020)

3. Духно Н. А. Обеспечение безопасности при эксплуатации объектов транспортной инфраструктуры / Н. А. Духно // Транспортное право и безопасность.2018. — № 2.- С. 8-19.

4. Кирилин М. А. Пути внедрения отечественных инновационных технологий на морском и внутреннем водном транспорте / M. А. Кирилин / Портал korabel. ru. — [Электронный ресурс].— Режим доступа: https://www.korabel.ru/ (дата обращения: 21.03.2020).

5. Панова И.В., Шустова М. В. Внутренний водный транспорт: административно-правовое регулирование основ безопасности / И. В. Панова, М. В. Шустова // Государство и право. - 2015.- № 6.—C. 147-152.

6. Поднадзорные организации. Перечень субъектов контроля и надзора по линии отдела надзора за судоходством на 01 января 2020 года / Сайт Госморречнадзор.— —Электронный ресурс].— Режим доступа: https://sea.rostransnadzor.ru/ (дата обращения: 21.03.2020).

7. Потемин А. внутренний водный транспорт России / А. Потемин / Сайт fb.ru. — [Электронный ресурс]. — Режим доступа: https://fb.ru (дата обращения: 20.03.2020).

8. Стручков В.И. Совершенствование системы безопасности судоходства в новых экономических условиях / В. И. Стручков / Дисс. ... канд. тех. наук: 05.22.19.- - Новосибирск, 2010.- 169с.

(c) Марков Владимир Петрович ( sf-vguvt@mail.ru).

Журнал «Современная наука: актуальные проблемы теории и практики» 